\title{
Urgences
}

\section{Travaillons au vertige du banal}

\section{Firmin Firquet}

Numéro 21, novembre 1988

Bagatelles et crases

URI : https://id.erudit.org/iderudit/025493ar

DOI : https://doi.org/10.7202/025493ar

Aller au sommaire du numéro

Éditeur(s)

Urgences

ISSN

0226-9554 (imprimé)

1927-3924 (numérique)

Découvrir la revue

Citer ce document

Firquet, F. (1988). Travaillons au vertige du banal. Urgences, (21), 45-64.

https://doi.org/10.7202/025493ar

Ce document est protégé par la loi sur le droit d'auteur. L'utilisation des services d'Érudit (y compris la reproduction) est assujettie à sa politique d'utilisation que vous pouvez consulter en ligne.

https://apropos.erudit.org/fr/usagers/politique-dutilisation/
Cet article est diffusé et préservé par Érudit.

Érudit est un consortium interuniversitaire sans but lucratif composé de l’Université de Montréal, l'Université Laval et l'Université du Québec à Montréal. Il a pour mission la promotion et la valorisation de la recherche. https://www.erudit.org/fr/ 


\section{FIRMIN FIRQUET (1947-1987)}

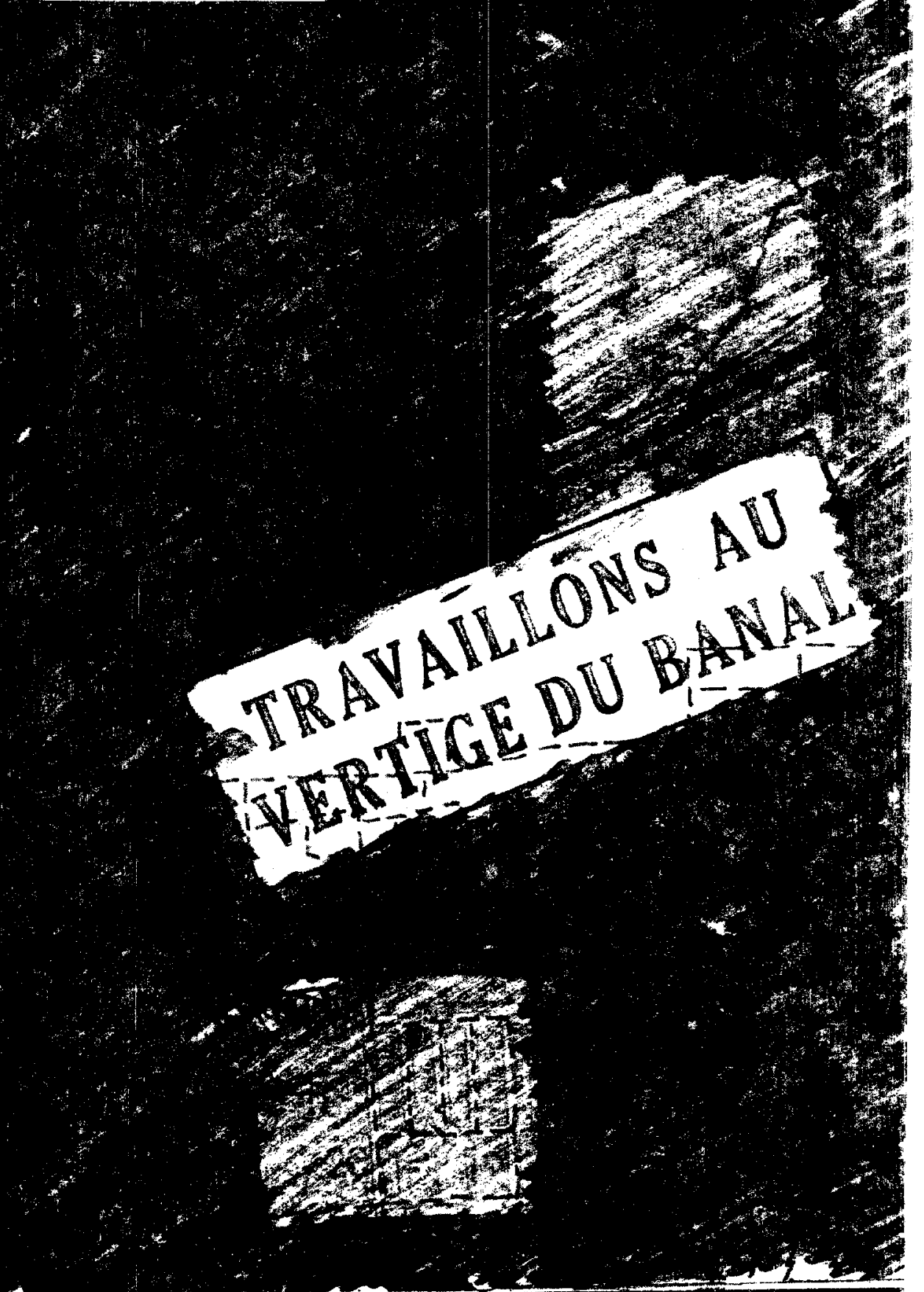




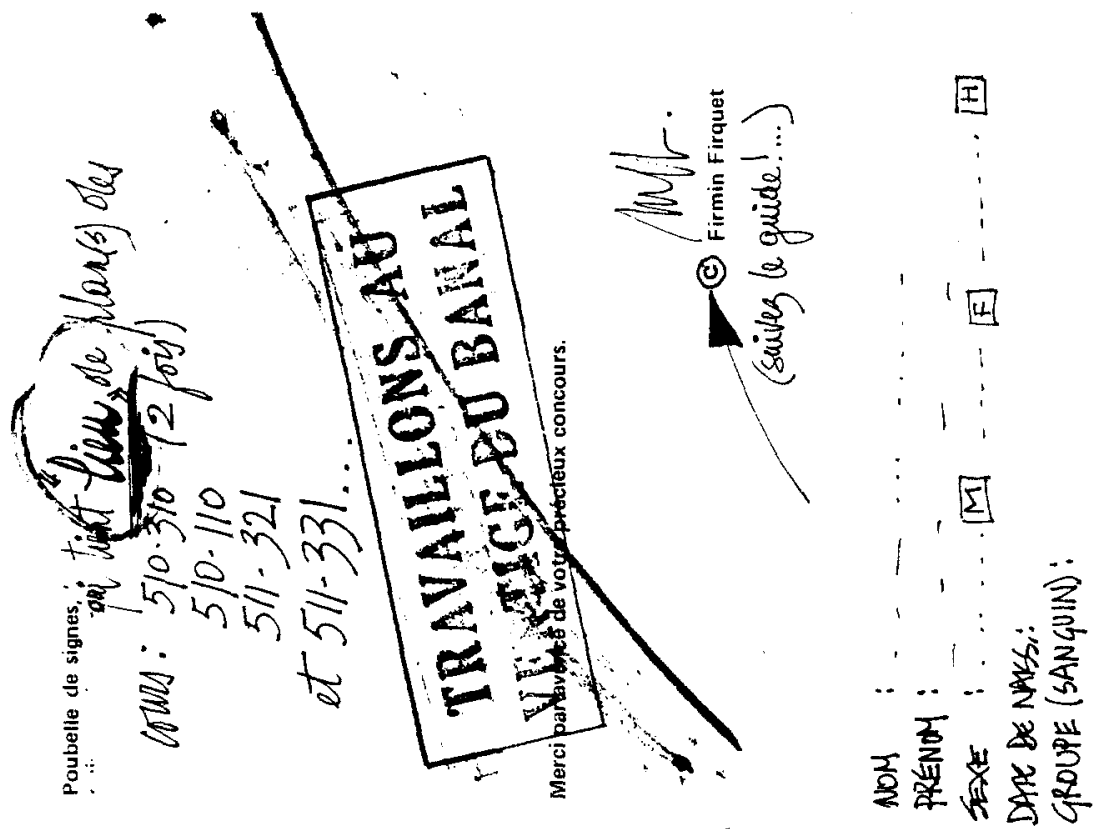

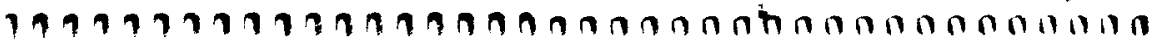

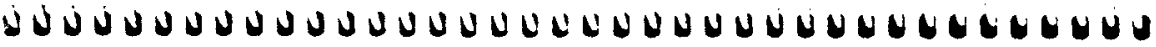

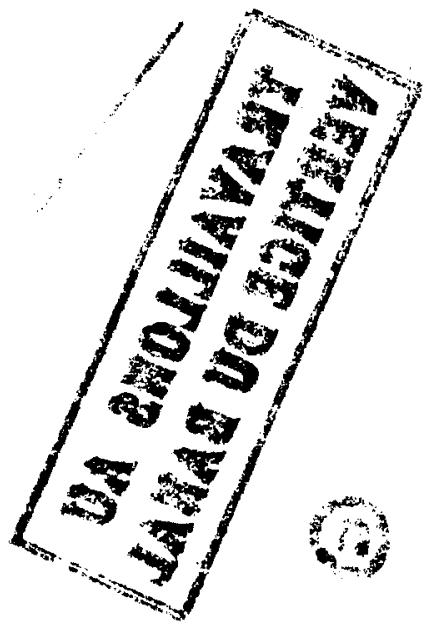




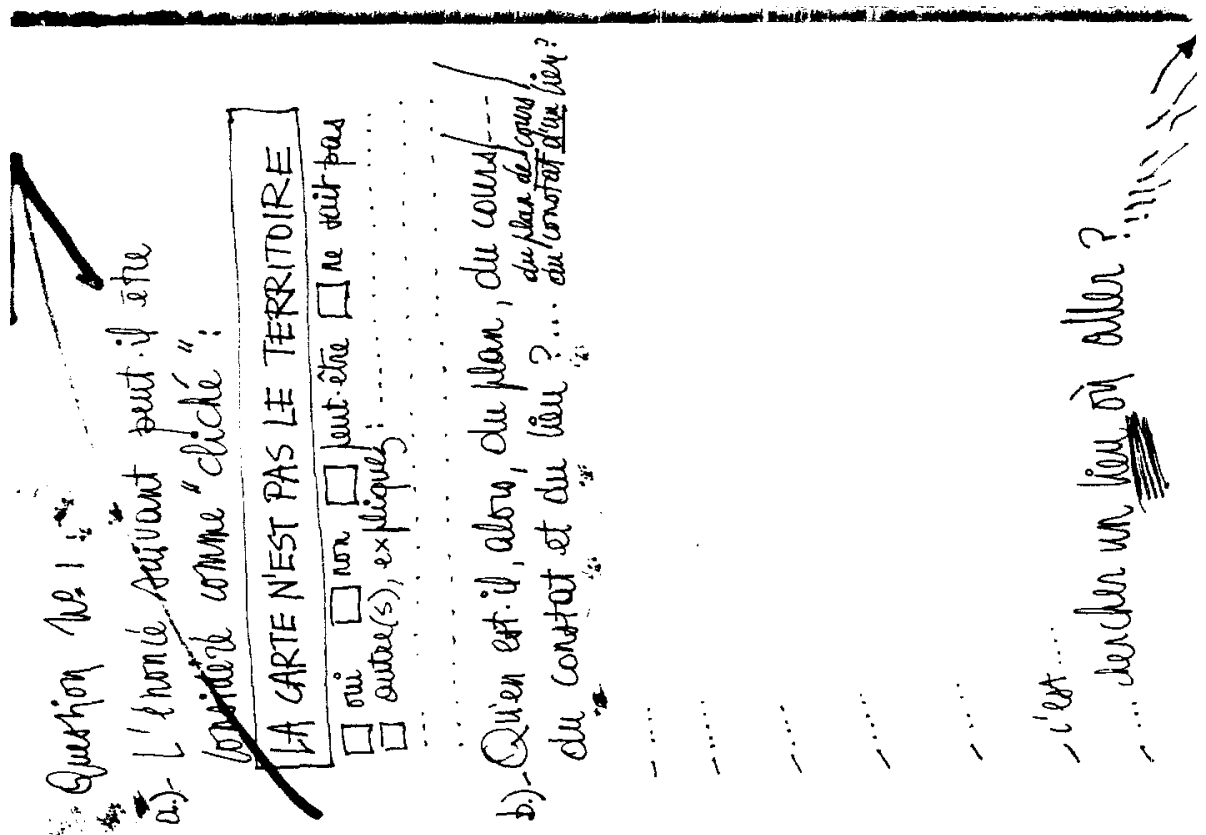

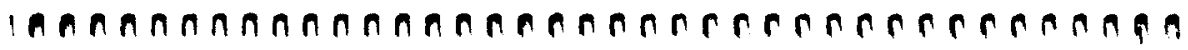

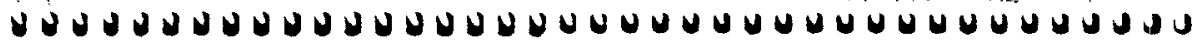




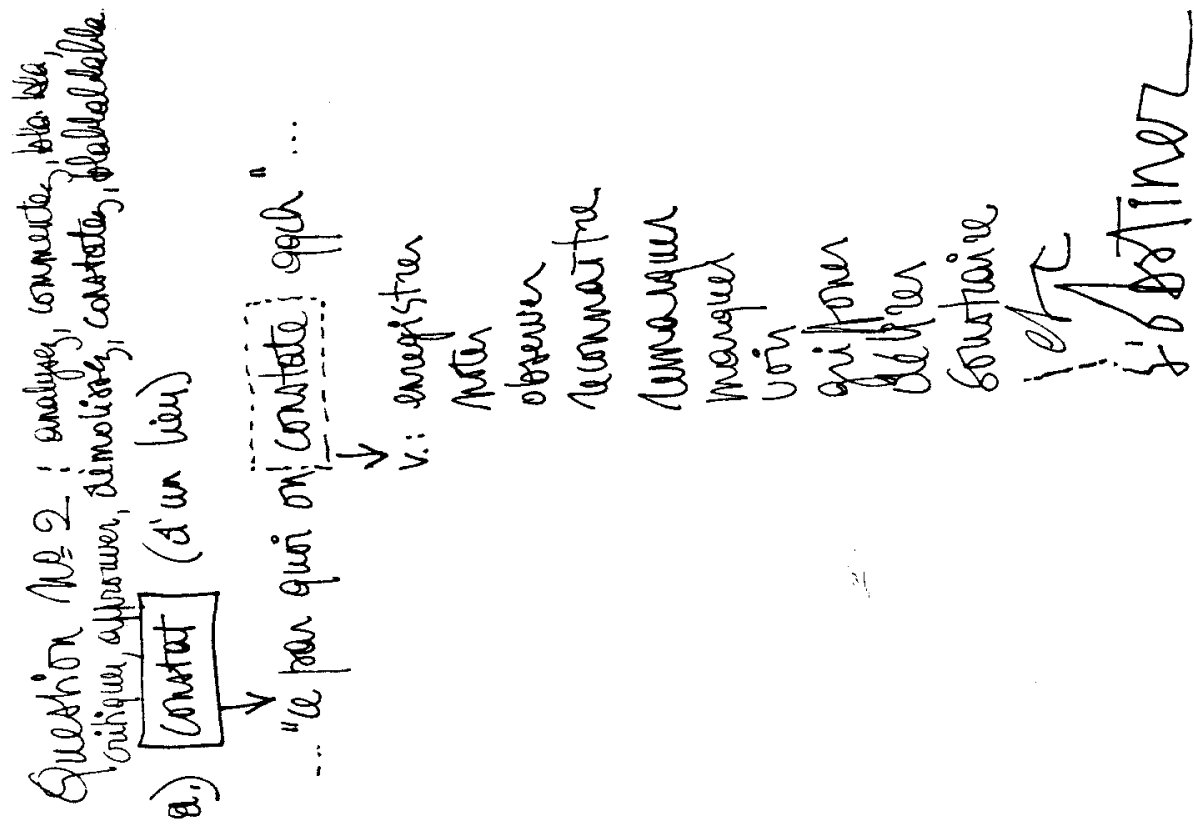

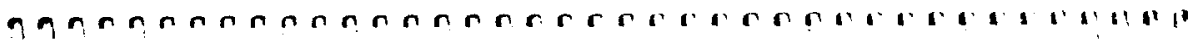

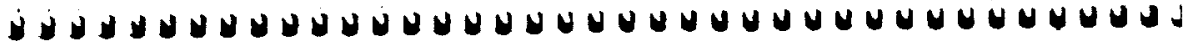




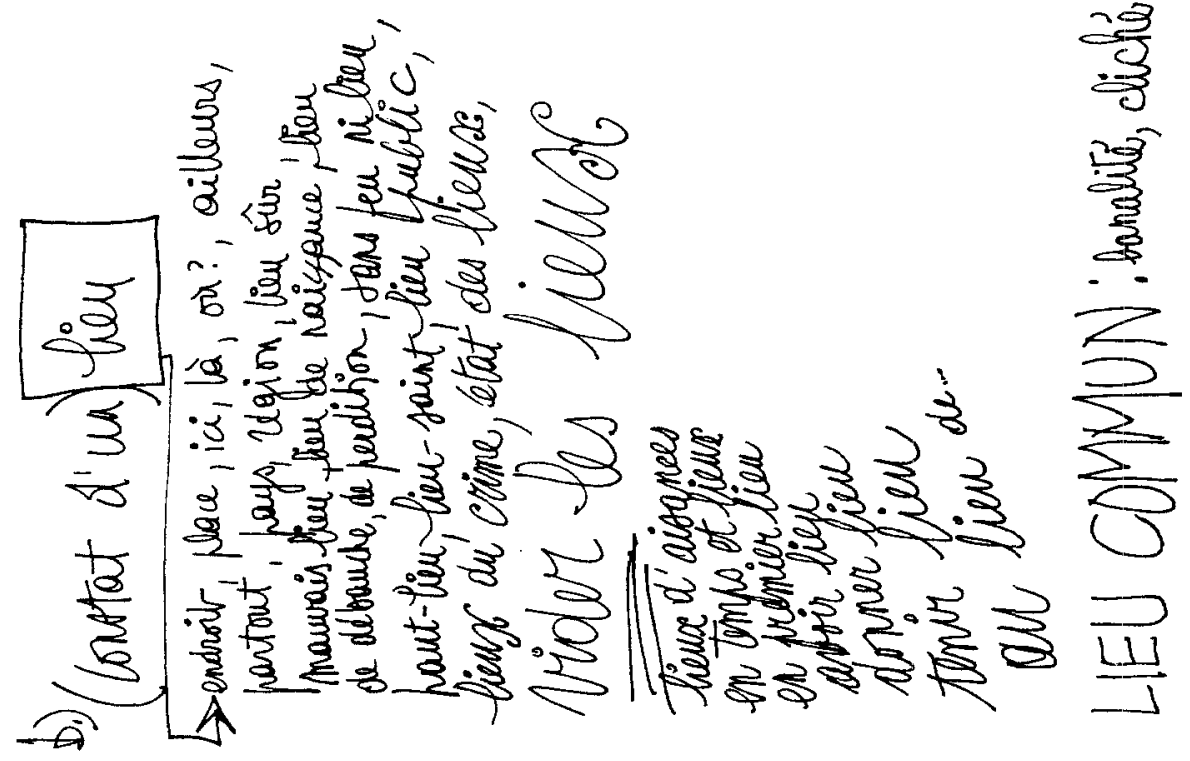

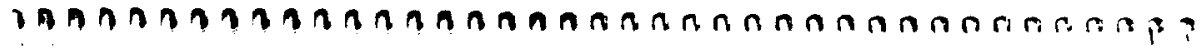

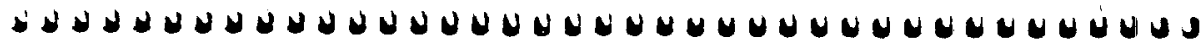




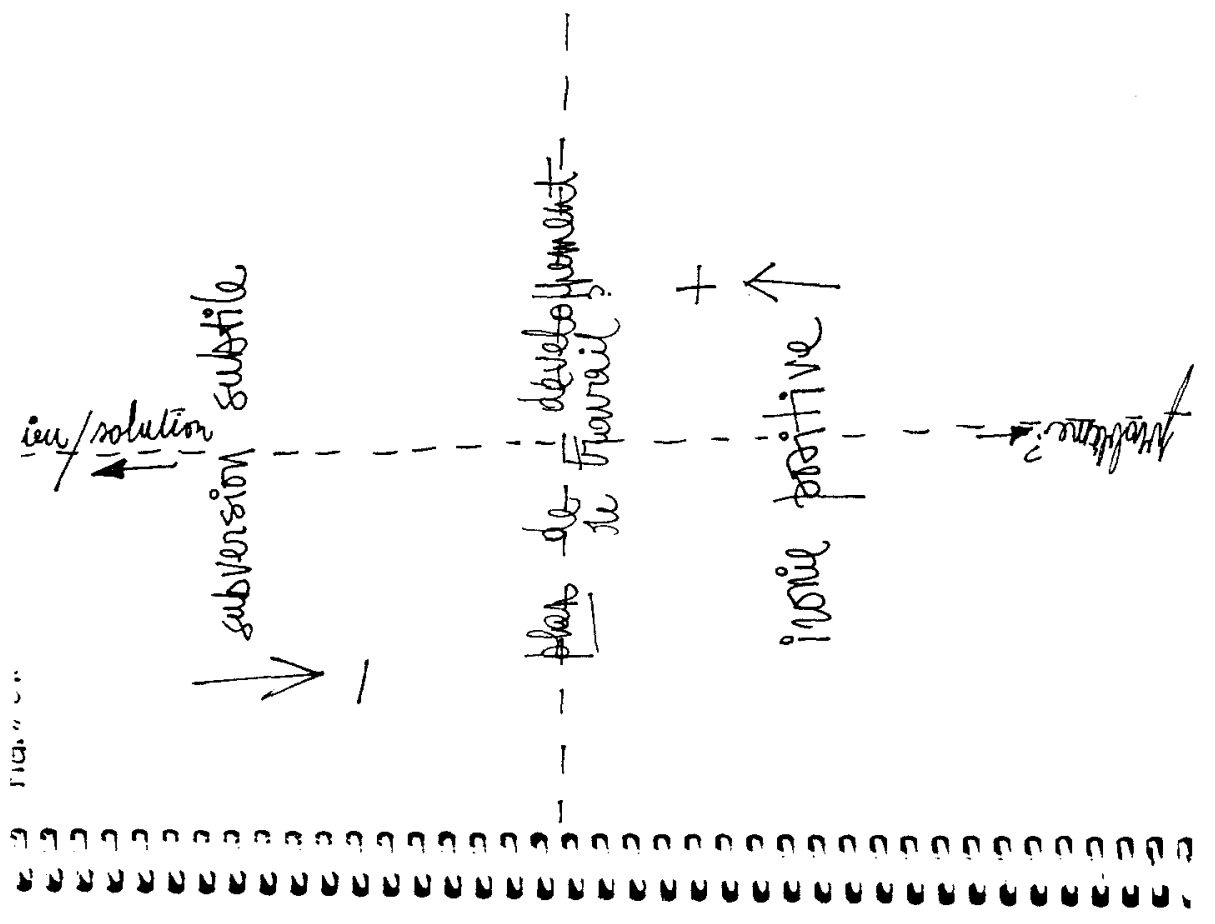




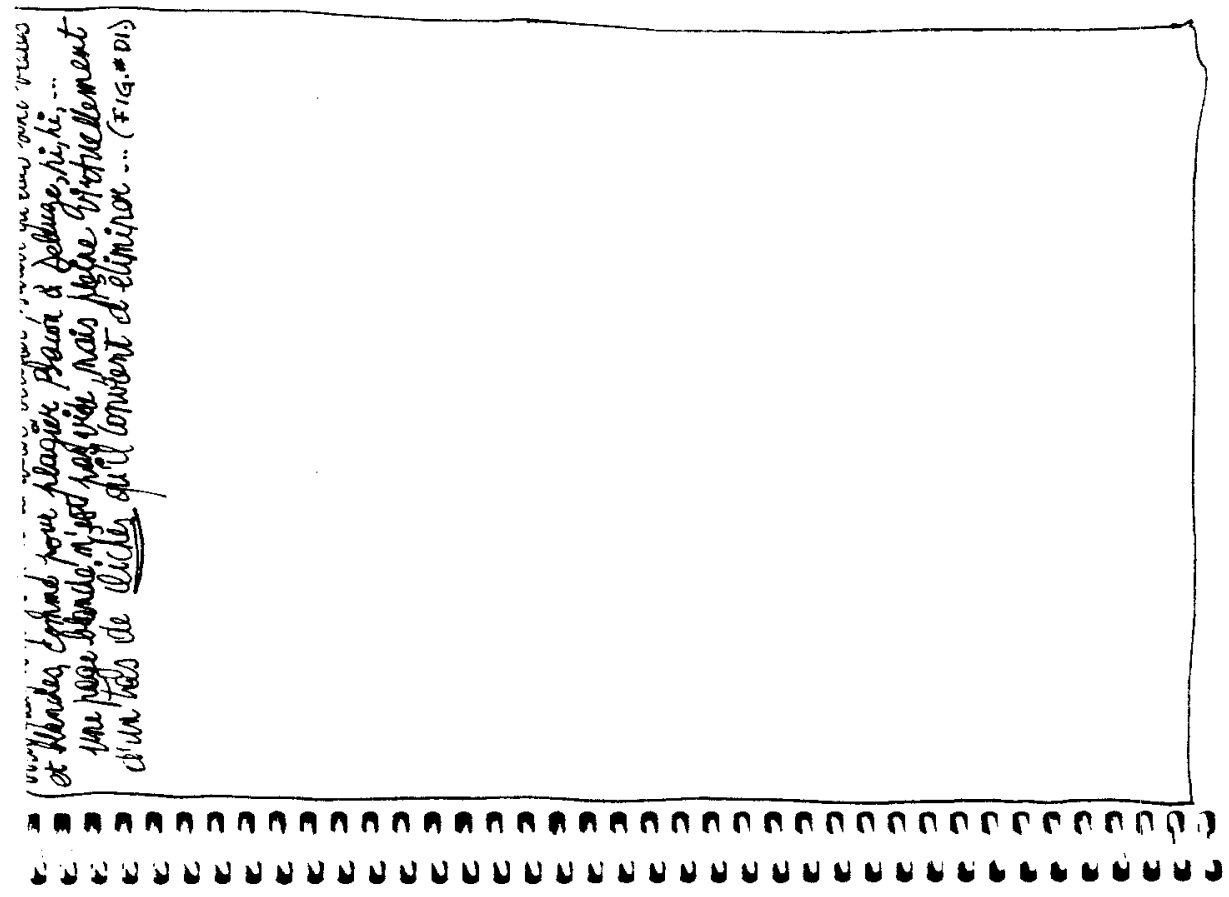




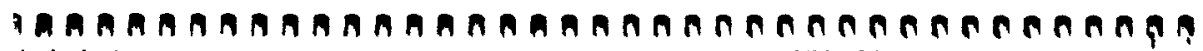

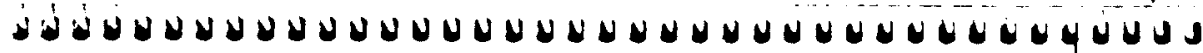

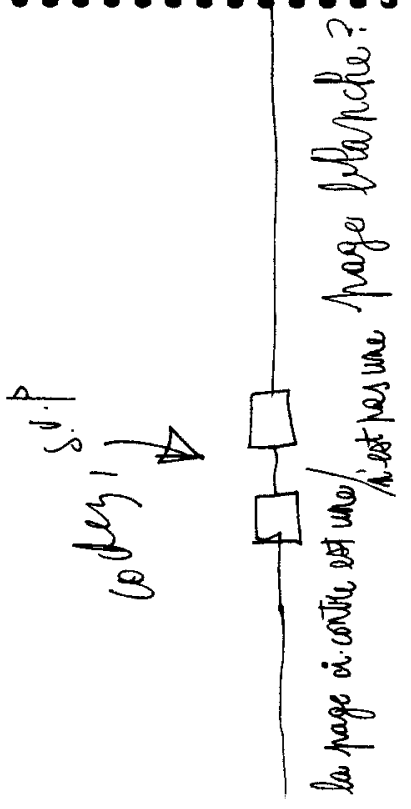




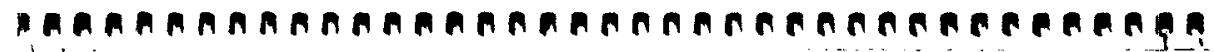
¿

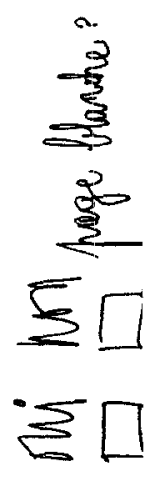




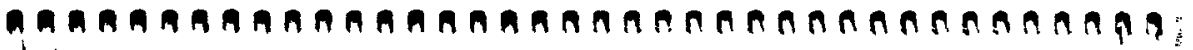

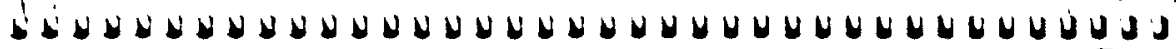

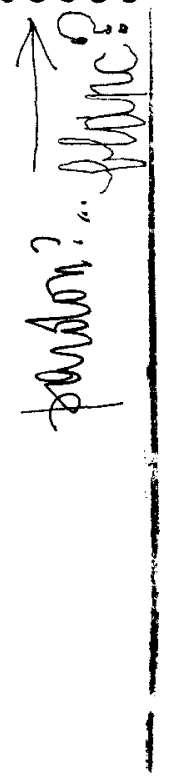




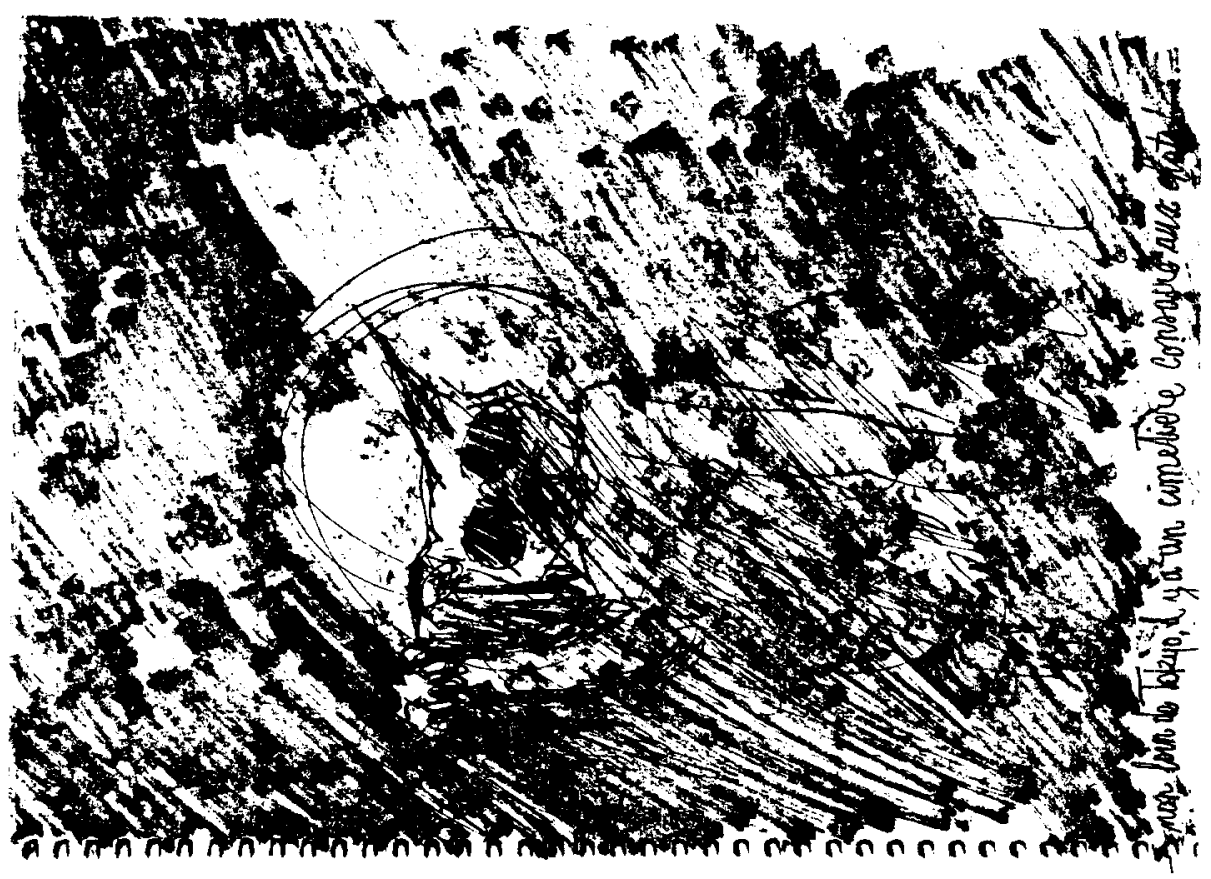

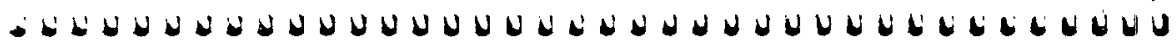



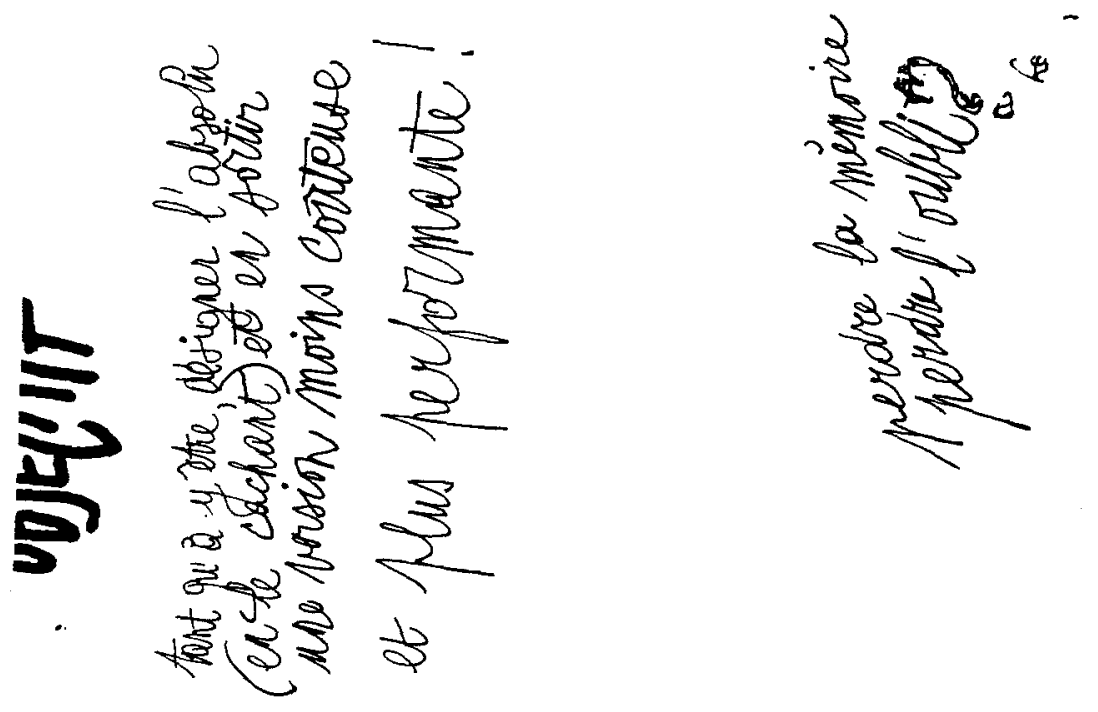

- 


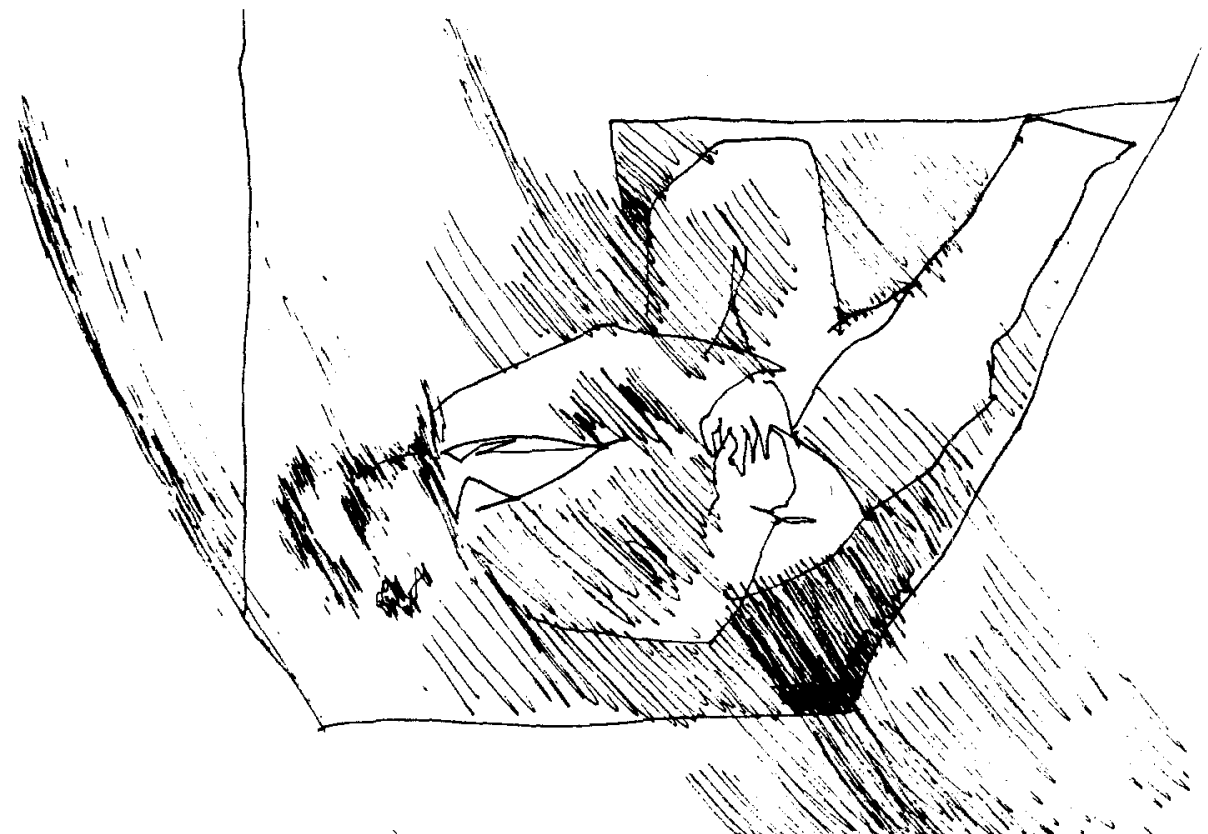

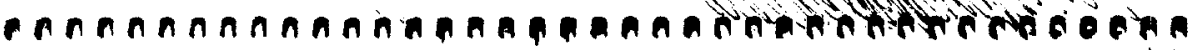

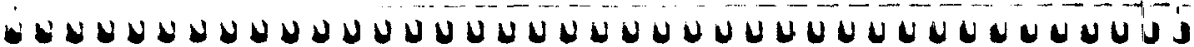

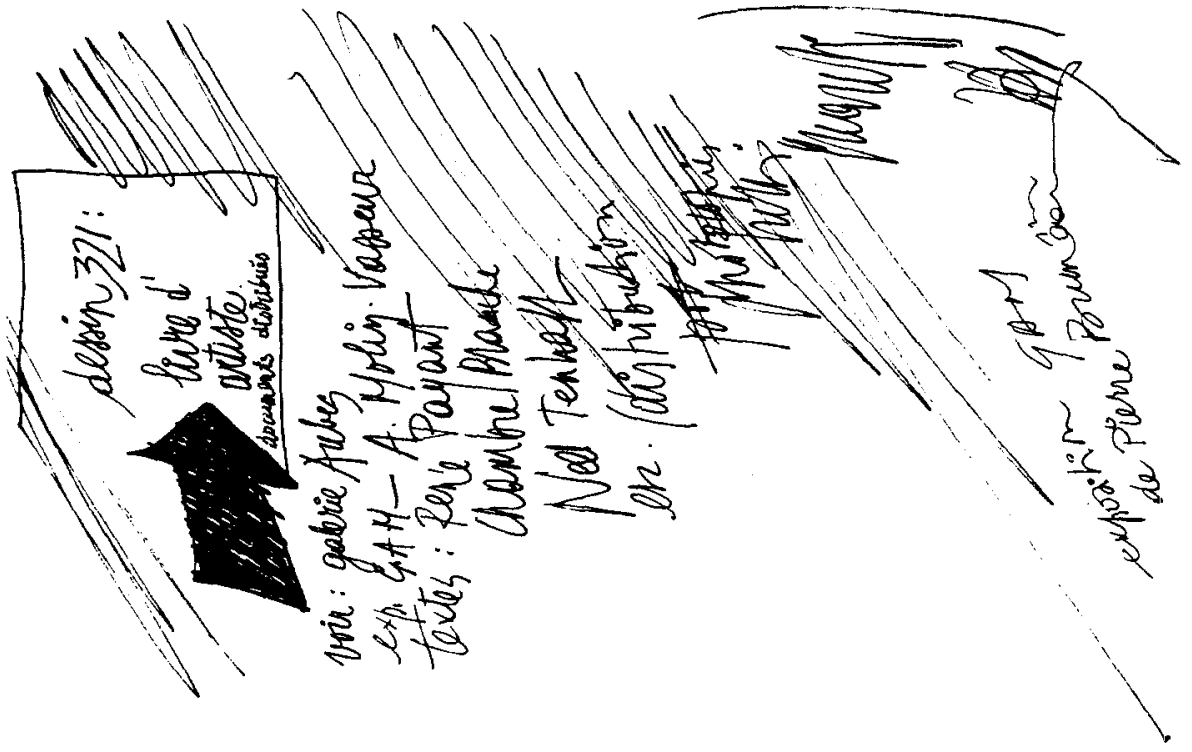




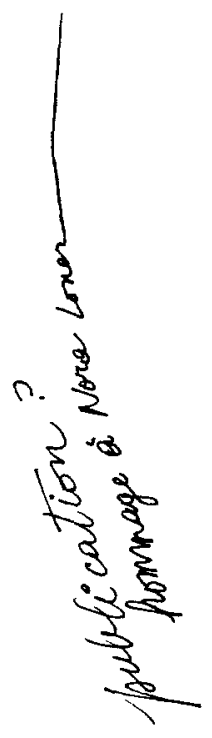

Mán

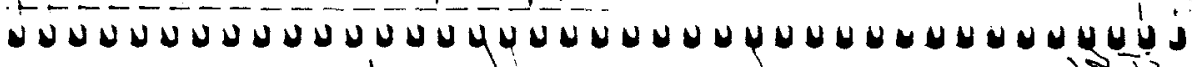

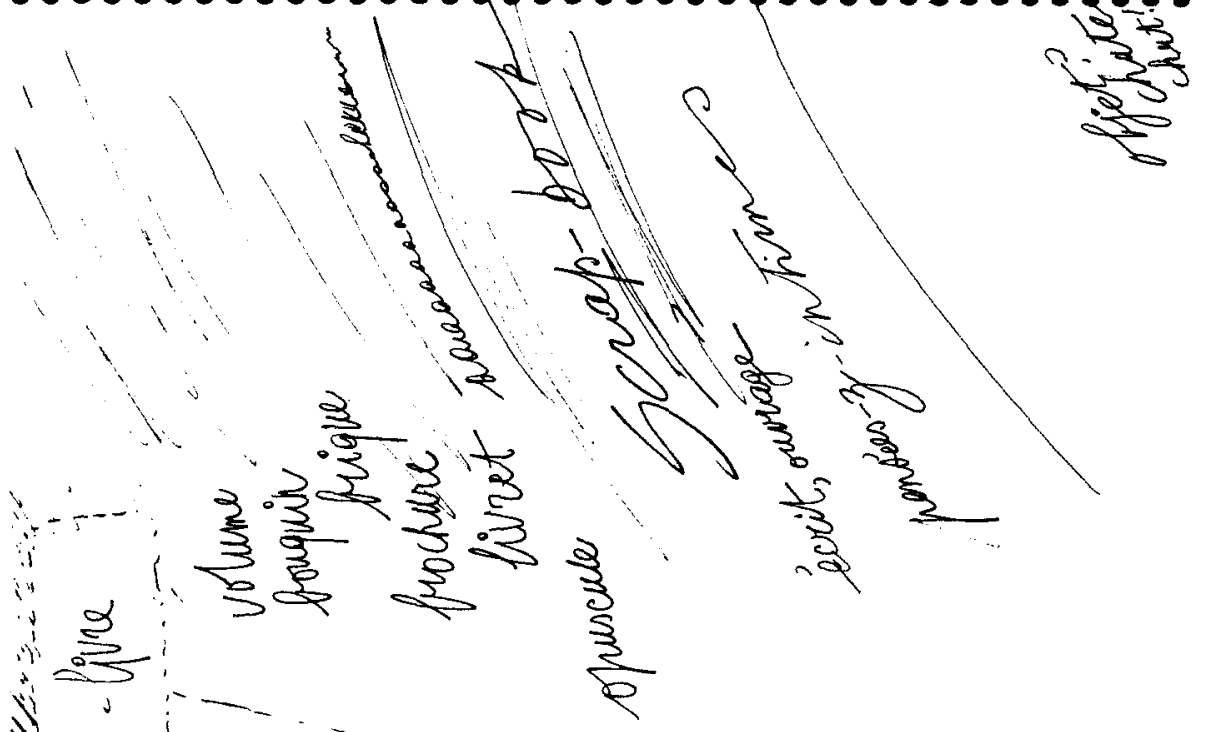




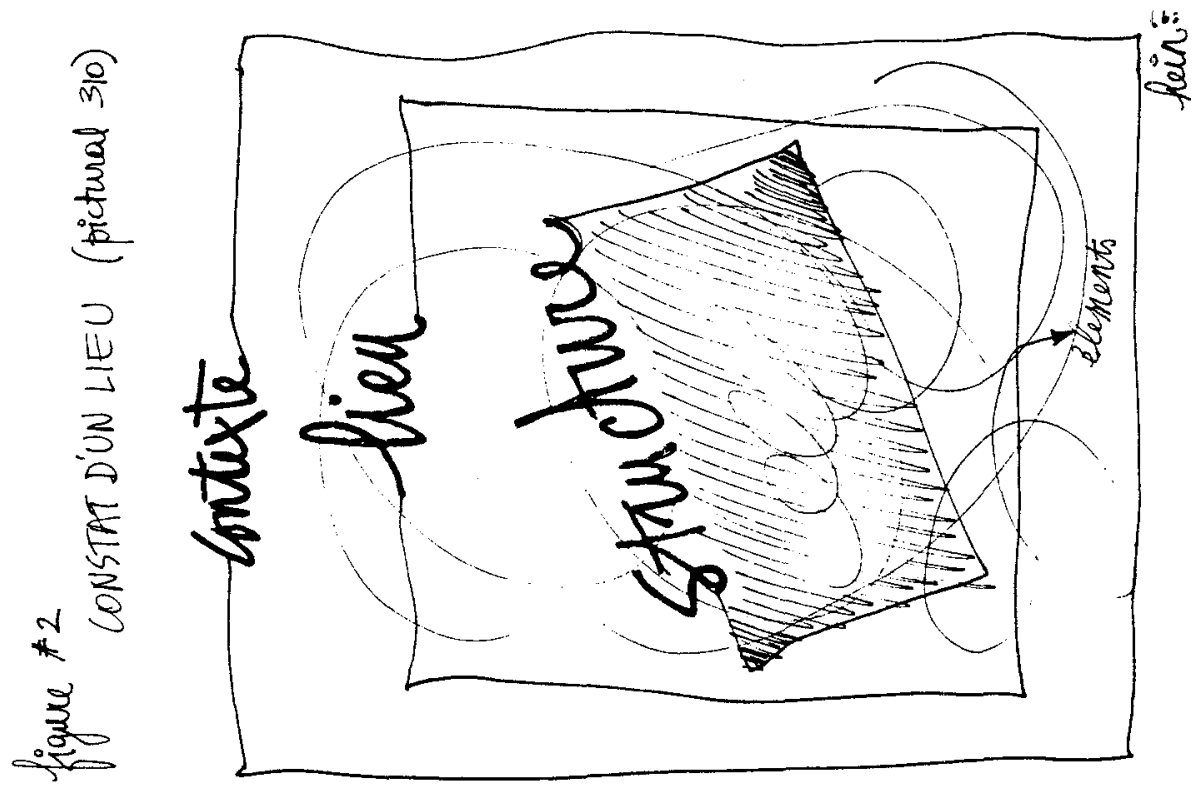

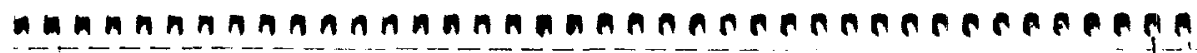
เ 


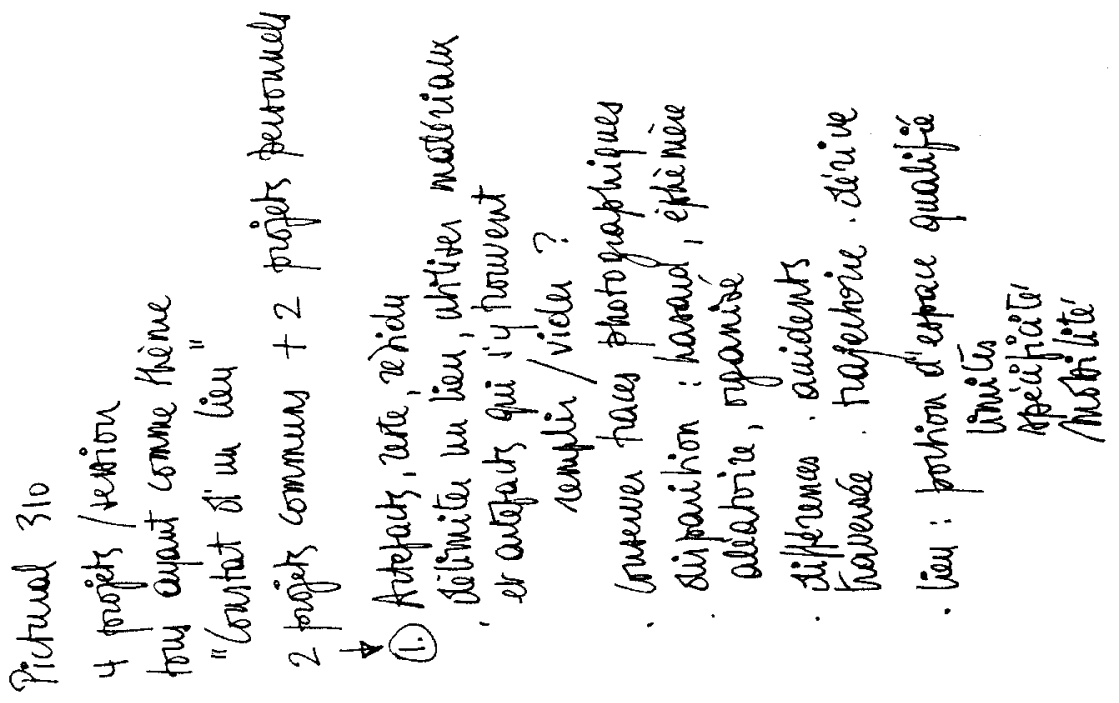

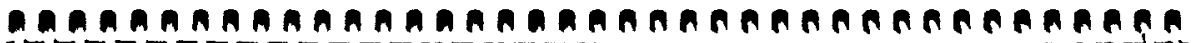

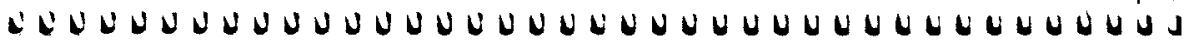




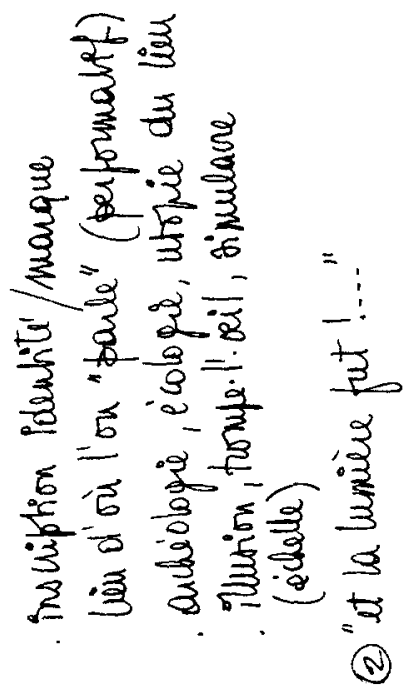

- 


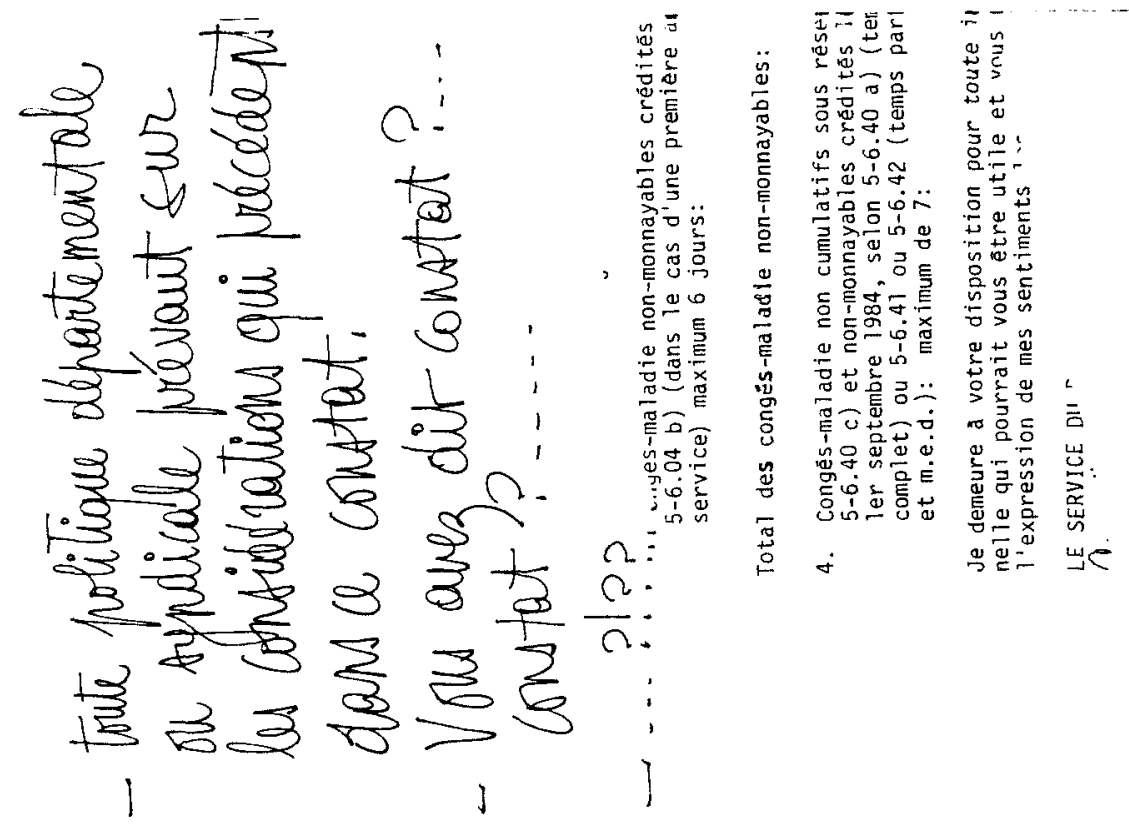

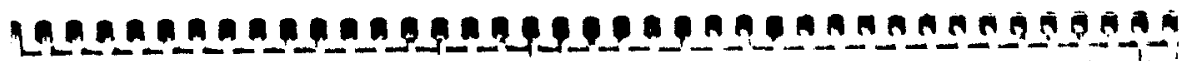

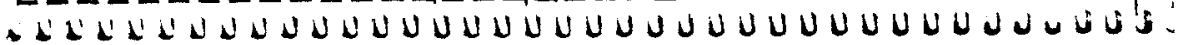



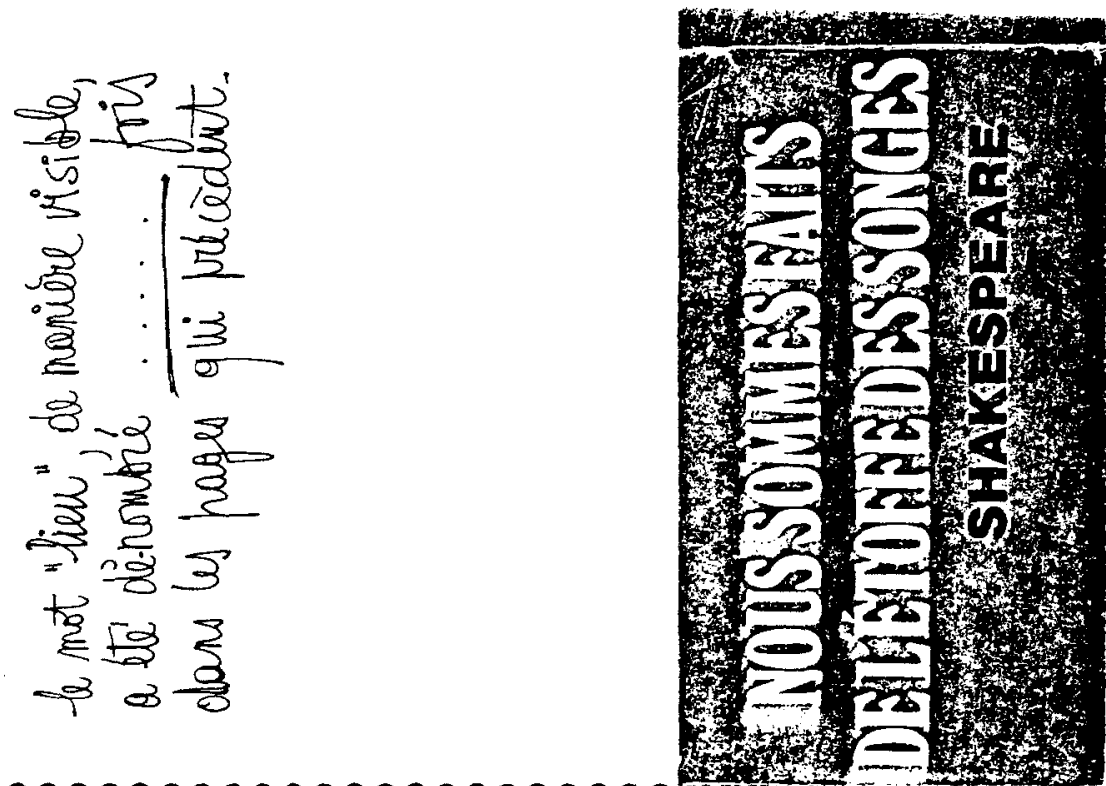

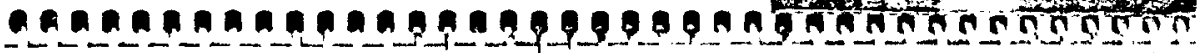

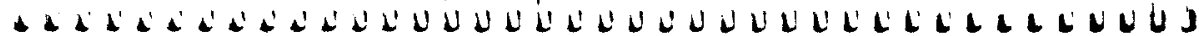

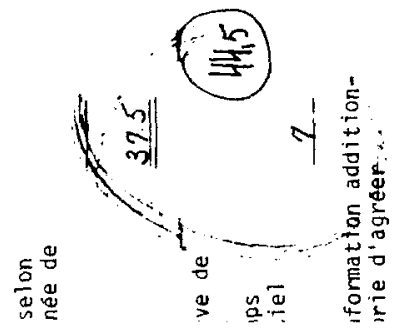




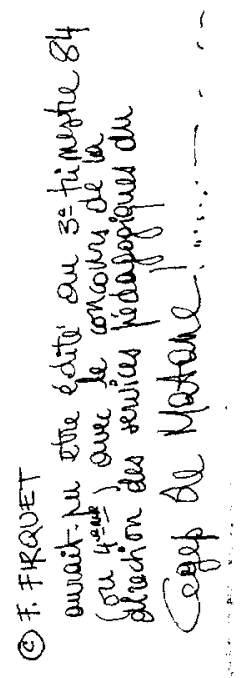

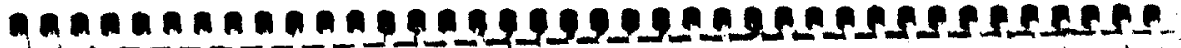

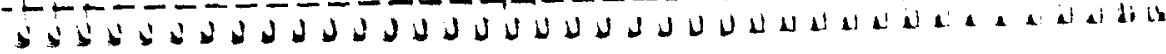

